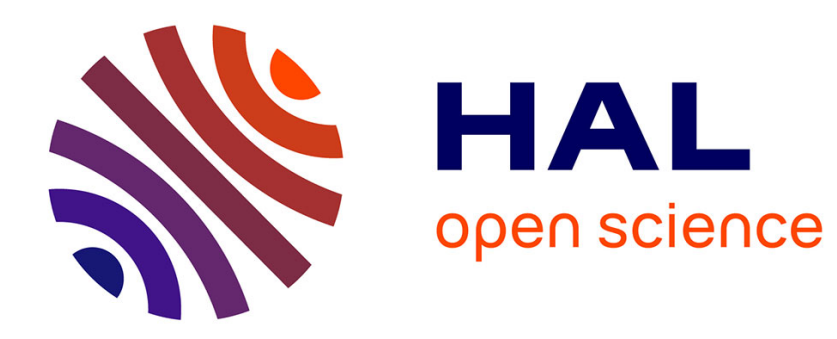

\title{
Mechanical Spectroscopy of a YSiAlON Glass
}

L. Donzel, R. Schaller

\section{To cite this version:}

L. Donzel, R. Schaller. Mechanical Spectroscopy of a YSiAlON Glass. Journal de Physique IV Proceedings, 1996, 06 (C8), pp.C8-663-C8-666. 10.1051/jp4:19968143 . jpa-00254576

\section{HAL Id: jpa-00254576 https://hal.science/jpa-00254576}

Submitted on 1 Jan 1996

HAL is a multi-disciplinary open access archive for the deposit and dissemination of scientific research documents, whether they are published or not. The documents may come from teaching and research institutions in France or abroad, or from public or private research centers.
L'archive ouverte pluridisciplinaire HAL, est destinée au dépôt et à la diffusion de documents scientifiques de niveau recherche, publiés ou non, émanant des établissements d'enseignement et de recherche français ou étrangers, des laboratoires publics ou privés. 
JOURNAL DE PHYSIQUE IV

Colloque C8, supplément au Journal de Physique III, Volume 6, décembre 1996

\title{
Mechanical Spectroscopy of a YSiAION Glass
}

\author{
L. Donzel and R. Schaller \\ Ecole Polytechnique Fédérale de Lausanne, Département de Physique, Institut de Génie Atomique, \\ 1015 Lausanne, Switzerland
}

\begin{abstract}
A YSiAlON glass has been studied by mechanical spectroscopy, through the glass transition. The $\alpha$-relaxation peak observed in the YSiAION glass can be interpreted well by a formalism of hierarchically correlated molecular mobility through the glass transition. In particular this formalism accounts for the observation of unusually high apparent activation energy. The viscoelastic properties of the glass are compared to the mechanical behavior of a silicon nitride ceramic.
\end{abstract}

\section{INTRODUCTION}

Silicon nitride ceramics are generally processed by sintering using a liquid densification medium: The resulting microstructure consists of needlelike and equiaxed grains imbedded in an intergranular glassy phase (generally SiAlON). As silicon nitride deforms by grain boundary sliding, the high temperature mechanical properties are strongly affected by the presence of this intergranular amorphous phase which softens and melts [1-3].

An investigation of the behavior of a glass similar to the intergranular phase could provide information for the interpretation of the mechanical properties of silicon nitride ceramics, in particular of the mechanical spectroscopy results [4-7].

In the present work, mechanical spectroscopy has been used to study the mechanical properties of a monolithic YSiAlON glass through the glass transition and the results have been analyzed following the Perez formalism [8] (molecular theory of the rheological behavior of amorphous materials through the glass transition, which permits one to successfully interpret many experimental results in oxide and polymeric glasses $[9,10])$.

\section{EXPERIMENTAL TECHNIQUE}

The YSiAlON samples used in this study have been prepared by Prof. S. Hampshire (Limerick, Eire) [11]. Their composition is: 10.99 at.\% Y, 18.46 at. $\% \mathrm{Si}, 8.35$ at.\% Al, 54.73 at.\% O, 7.47 at.\% N. Samples of the size $30 \times 4 \times 1 \mathrm{~mm}^{3}$ were measured in a differential, forced, inverted, torsion pendulum [12]. In this apparatus, the sample is mounted in series with another one that acts as an elastic reference. Measurements were performed under vacuum $\left(10^{-6} \mathrm{Torr}\right)$, from room temperature to $1350 \mathrm{~K}$ and at frequencies between $10^{-3}$ and $10 \mathrm{~Hz}$. The shear storage modulus $G^{\prime}$ and the shear loss modulus $G^{\prime \prime}$ were measured either as a function of temperature at fixed frequencies, or as a function of frequency at fixed temperatures.

\section{RESULTS AND ANALYSIS}

The typical spectra (the storage $G^{\prime}$ and loss $G^{\prime \prime}$ shear modulus as a function of temperature) in a YSiAION glass are shown in Figure 1 . Above the glass transition $(\approx 1220 \mathrm{~K}$, determined by dilatometry [13]), a mechanical loss peak and a strong modulus decrease are observed. For a measurement frequency 
of $1 \mathrm{~Hz}$, the peak is found at a temperature of $1300 \mathrm{~K}$. Isothermal spectra $G^{\prime}(\omega)$ and $G^{\prime \prime}(\omega)$ of the same sample are shown in Figure 2. The positions of the $G^{\prime \prime}(\omega)$ peak and of the modulus defect are shifted to higher frequencies when the temperature of the isothermal measurement is increased. The relaxation is therefore a thermally activated phenomenon.

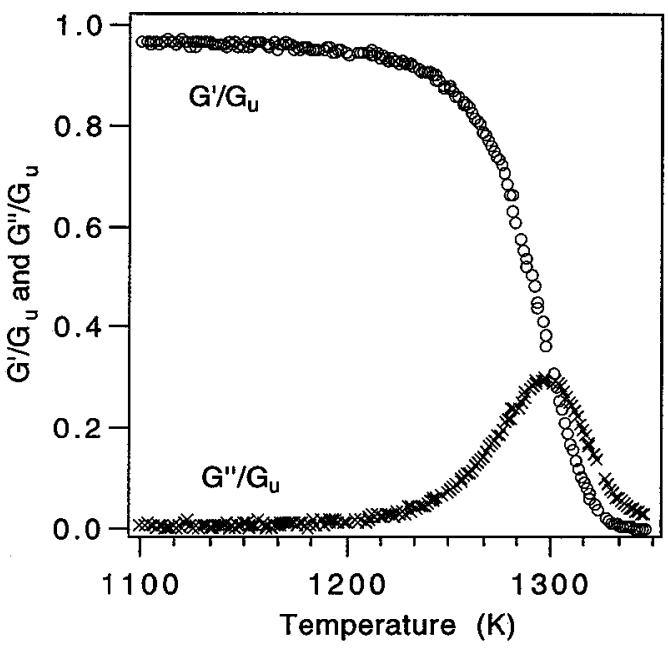

Figure 1: Dependence of the normalized storage and loss shear modulus $\left\{G^{\prime}(T) / G_{u}\right.$ and $\left.\left.G^{\prime \prime}(T) / G_{u}\right)\right\}$ of the YSiAlON glass as a function of temperature. $G_{u}$ is the unrelaxed shear modulus. The measurement frequency was $1 \mathrm{~Hz}$, and the heating rate was $1 \mathrm{~K} / \mathrm{min}$.

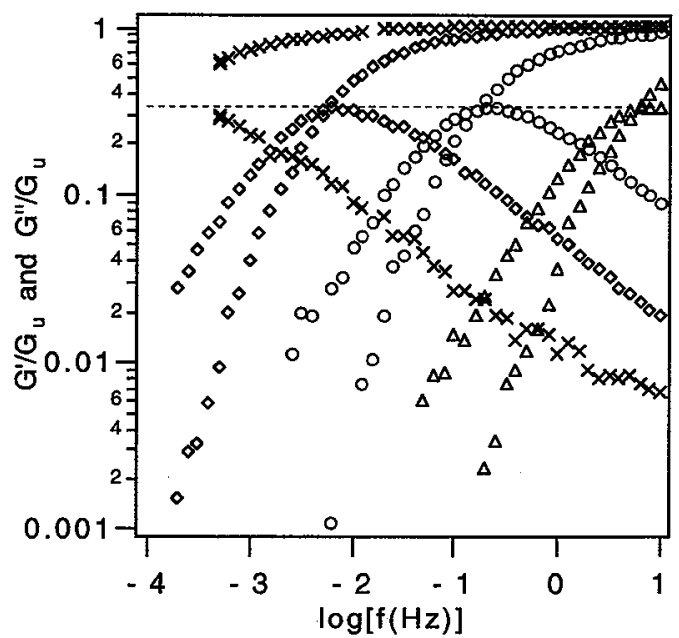

Figure 2: Normalized isothermal spectra $\int\left(G^{\prime}(\omega) / G_{u}\right.$ and $\left.G^{\prime \prime}(\omega) / G_{u}\right) l$ of the YSiAlON glass for different temperatures. x $1200 \mathrm{~K}, 01240 \mathrm{~K}$, o $1280 \mathrm{~K}, \Delta 1325 \mathrm{~K}$. One can see the shift of the spectra to higher frequencies for higher measurement temperatures.

In an Arrhenius plot, one can see that logarithm of the relaxation time is a linear function of the inverse temperature over a wide frequency range (Fig. 3). The activation energy is $1116 \pm 20 \mathrm{KJ} / \mathrm{mol}$ and the limit relaxation time is $2 \cdot 10^{-46} \mathrm{~s}$. These are in fact apparent values. Effectively, the thermally activated relaxation phenomenon observed in glasses above the glass transition is the main or $\alpha$-relaxation, which is associated with the onset of longrange molecular movements. These movements are hierarchically correlated and this leads to unusually high apparent activation energies and unusually low apparent limit relaxation times. These values can however be related to the elementary molecular motion values as it is done in the Perez et al. [8] formalism and in the coupling model [14].

Perez et al. have proposed a molecular theory of the rheological behavior of amorphous material through the glass transition based on the concept of hierarchical correlated molecular motion first proposed by Palmer et al. [15]. This theory leads to the following expression of the characteristic time for molecular motion $\tau_{m o l}$ (similar to the expression derived from the coupling model [14], $b=1-n$ ):

$$
\tau_{m o l}=t_{0} \cdot\left(\frac{\tau_{I}}{t_{0}}\right)^{\frac{1}{b}},
$$

where $\tau_{1}=\tau_{1}^{0} \cdot \exp \left(\frac{E_{1}}{k T}\right)$ is the characteristic time of the elementary molecular motion, $t_{0}$ is a scaling parameter and $0<b<1$ is the correlation parameter. The parameter $b$ expresses the importance of the effect of the hierarchical correlation upon the mobility. If $b=1$ there is no correlation and if $b \rightarrow 0$ the correlation is very strong. This parameter permits one to relate the apparent activation energy of the $\alpha$-relaxation phenomena to the elementary molecular motion activation energy $E_{I}$ :

$$
E_{a p p}(T)=\frac{\mathrm{d} \ln \left[\tau_{m o l}(T)\right]}{\mathrm{d}(1 / k T)}=\frac{E_{1}}{b}-\frac{\ln \left(\tau_{1} / t_{0}\right)}{b^{2}} \cdot \frac{\mathrm{d} b}{\mathrm{~d}(1 / k T)} .
$$

The correlation parameter can be obtained from the Cole-Cole representation of the isothermal spectra, i.e. the $G^{\prime \prime}\left(G^{\prime}\right)$ diagram. 


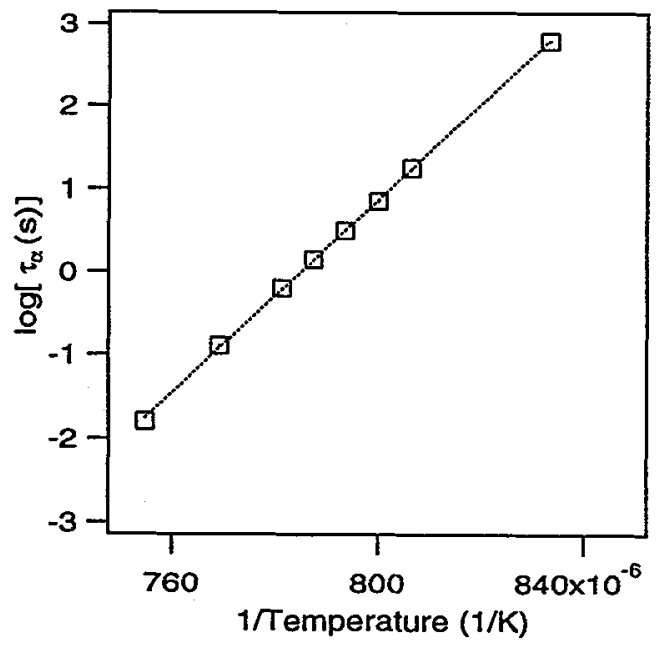

Figure 3: Arrhenius plot obtained from the peak shift in isothermal measurements. Deduced apparent activation parameters: $E_{a p p}=1116 \pm 20 \mathrm{KJ} / \mathrm{mol}$ and $\tau_{\text {oapp }}=2 \cdot 10^{-46}$ s.

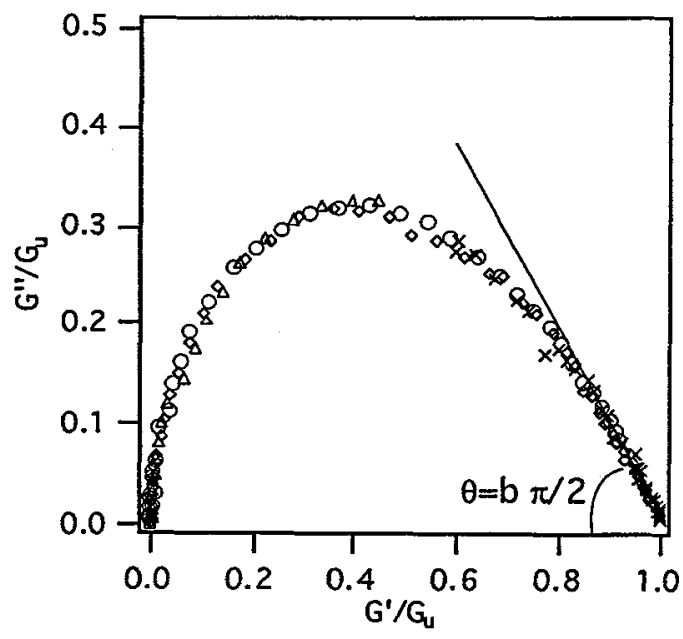

Figure 4: Cole-Cole plot, i.e. the loss part of the normalized shear modulus represented as a function of the storage part (for the spectra of Fig.2). The angle between the curve and the horizontal axis when $\mathbf{G}^{\prime} / \mathrm{G}_{\mathbf{u}} \rightarrow 1$ gives the correlation parameter $b$.

For all of the investigated temperatures, a value of $0.48 \pm 0.01$ was found for the correlation parameter. As a consequence, it follows that $\mathrm{d} b / \mathrm{dT}=0$, and from Eq. (2), the elementary molecular motion activation energy in YSiAlON glass is then $E_{I}=E_{a p p} \cdot b \approx 530 \mathrm{KJ} / \mathrm{mol}$.

\section{DISCUSSION}

The above results show that the relaxation phenomenon observed at high temperature in the YSiAlON glass can be interpreted as the $\alpha$-relaxation and that the degree of hierarchical correlation of the molecular movements is characterized by $b=0.48$ as deduced from the Cole-Cole plot.

The calculated activation energy for the elementary motion $\left(E_{l}=E_{a p p} \cdot b \approx 530 \mathrm{KJ} / \mathrm{mol}\right)$ is similar to the activation energy determined by Rouxel from creep test on YSiAlON glasses, 400-600 KJ/mol [16].

As $b$ does not depend upon the temperature, the relaxation time follows an Arrhenius law, whereas it is not the case for most of the amorphous materials. This indicates that the YSiAlON is a rather strong glass (i.e. no rapid degradation of the mechanical properties above the glass transition)

The value found for $b(0.48)$ is larger than those found in CaSiAlONs $(\approx 0.34)$ [10]. However this is not surprising as it is known that YSiAlON thermomechanical properties are higher than the CaSiAION ones, i.e. the YSiAlON are stronger glasses than the CaSiAlON glasses.

In Figure 5, one can see that the expression of the complex shear modulus calculated in the frame of the Perez formalism permits to reproduce well the experimental mastercurves .

Finally, a comparison between the $\alpha$-relaxation in the YSiAION glass and the loss peak in a silicon nitride ceramic is made. In Table $\mathrm{I}$, the characteristic parameters of the $\mathrm{Si}_{3} \mathrm{~N}_{4}$ peak and of the YSiAlON $\alpha$-relaxation peak are given.

The apparent activation energy and the correlation parameter found for the relaxation peak in silicon nitride by Lakki $[4,17]$ are similar to the values found in this study for the YSiAlON glass $\alpha$-relaxation. The difference of $\tau_{0}$ app is certainly due to the composition difference. In fact, a slight change of composition can change the relaxation time by more than a factor ten [10]. 


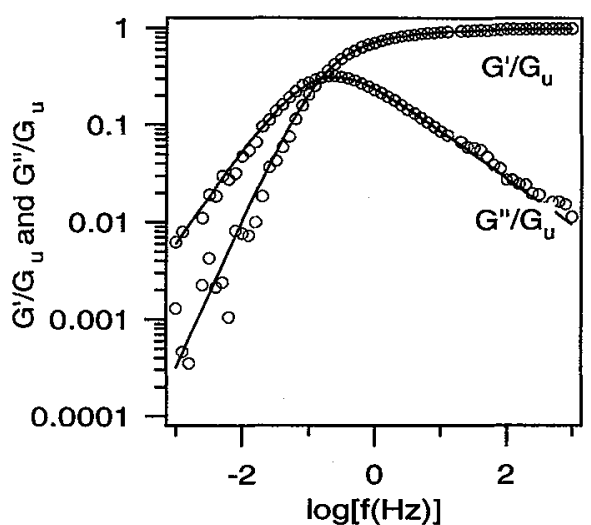

Figure 5: (o) Experimental mastercurves $\left(\mathrm{T}_{\text {ref. }}\right.$ : $1280 \mathrm{~K})$, (---) calculated curves using the equation $G^{*}(i \omega) / G_{u}=\left[I+\left(i \omega \tau_{\alpha}\right)^{-b}+\delta\left(i \omega \tau_{\alpha}\right)^{-I}\right]^{-I} \quad$ [8] with $b=0.48, \delta=1.2$ and $\tau_{\alpha}(1280 \mathrm{~K})=1.2 \mathrm{~s}$.

\begin{tabular}{lccc}
\hline \hline Sample & $\begin{array}{c}\mathrm{E}_{\mathrm{app}} \\
(\mathrm{KJ} / \mathrm{mol})\end{array}$ & $\begin{array}{c}\mathrm{b} \\
\pm 0.01\end{array}$ & $\begin{array}{c}\tau_{0 \text { app }} \\
(\mathrm{s})\end{array}$ \\
\hline YSiAlON & $1116 \pm 20$ & 0.48 & $210^{-46}$ \\
$\mathrm{Si}_{3} \mathrm{~N}_{4}$ & $1117 \pm 22$ & 0.48 & $0.810^{-47}$ \\
\hline \hline
\end{tabular}

These results, together with the previous observation by Lakki $[4,17]$ of the disappearance of the peak after recystallization of the glassy pockets, permits one to attribute the $\mathrm{Si}_{3} \mathrm{~N}_{4}$ peak to the $\alpha$-relaxation of these glassy pockets. The high activation energy found for the silicon nitride ceramic peak then results from the fact that in the amorphous intergranular phase the molecular motions are hierarchically correlated, which leads to an apparent activation energy higher than the elementary activation energy $E_{1}$.

\section{CONCLUSIONS}

The $\alpha$-relaxation of YSiAlON glass has been studied. The correlation parameter which describes the importance of hierarchical correlation upon the molecular mobility has been determined. The mastercurves can be simulated well by the Perez formalism. From the comparison between former results in $\mathrm{Si}_{3} \mathrm{~N}_{4}$ ceramics containing YSiAION intergranular pockets and films, the peak observed in this material can be attributed to the $\alpha$-relaxation in the amorphous pockets. The unusually high activation energy of the peak is due to the hierarchical correlation of the molecular movements in the amorphous intergranular phase.

\section{Acknowledgments}

This work was financially supported by the Swiss National Foundation. The authors wish to thank T. Rouxel ( ENSCI, Limoges) for providing them with the samples.

\section{References}

[1]. Crampon J., Duclos R., and Rakotoharisoa N., J. Mater. Sci. 28 (1993) 909-916.

[2]. Lange F., Davis B., and Clarke D., J. Mater. Sci. 15 (1980) 601-610.

[3]. Besson J. and Goursat P., Rev. Int. Hautes Tempér. Réfract. 23 (1986) 145-157.

[4]. Lakki A., Schaller R., Bernard-Granger G., et al., Acta metall. mater. 43 (1995) 419-426.

[5]. Sakaguchi S., Murayama N., and Wakai F., J. Ceram. Soc. Jpn. Inter. Ed. 95 (1987) 1162-1165.

[6]. Shioiri J., Futura O., and Satoh K., in Non-destructive Characterisation of Materials II (Plenum Press, 1987) pp. $325-333$.

[7]. Tsai R. and Raj R., J. Am. Ceram. Soc. 63 (1980) 513-517.

[8]. Perez J., Cavaille J. Y., Etienne S., et al., Revue Phys. Appl. 23 (1988) 125-135.

[9]. Perez J., Muzeau E., and Cavaille J. Y., Plastics, Rubber and Composites Proc. and Appl. 18 (1992) $139-148$.

[10]. Sekkat A., Ph. D. thesis, INSA, Lyon, France, 1992.

[11]. Hamphire S., Drew R., and Jack K., Physics Chem. Glasses 26 (1985) 182-186.

[12]. Gadaud P., Guisolan B., Kulik A., et al, Rev. Sci. Instrum. 61 (1990) 2671-2675.

[13]. Rouxel T., Lemercier H., and Besson J. L., in Tailoring of Mechanical Properties of Si3N4 Ceramics (M. J. Hoffmann, Kluver Academic, 1994), p. 175-186.

[14]. Ngai K. L., Rajagopal A.K., and Teitler S., J. Chem. Phys. 88 (1988) 5086-5094.

[15]. Palmer R. G., Stein D. L., Abrahams E., et al., Phys. Rev. Lett. 53 (1984) 958-961.

[16]. Rouxel T., Huger M., and Besson J L., J. Mater. Sci. 27 (1992) 279-284.

[17]. Lakki A., Ph. D. thesis, EPFL, Lausanne, Switzerland, 1994. 